\title{
EPISTEMOLOGIA DA FORMAÇÃO DOCENTE: O QUE SE PODE APRENDER COM O EMPIRISMO DE FREINET
}

\author{
EPISTEMOLOGÍA DE LA FORMACIÓN DOCENTE: LO QUE SE PUEDE \\ APRENDER CON EL EMPIRISMO DE FREINET
}

\section{EPISTEMOLOGY OF TEACHING EDUCATION: WHAT CAN BE LEARNED WITH FREINET'S EMPIRISM}

Ivan FORTUNATO ${ }^{1}$

\begin{abstract}
RESUMO: Este ensaio trata da epistemologia da formação de professores a partir do trabalho educativo realizado por Célestin Freinet. A complexidade do exercício docente cotidiano é colocada em evidência sendo que, das inúmeras trilhas epistemológicas possíveis para o desenvolvimento da profissão, o empirismo de Freinet é aludido como uma das formas mais interessantes, instigantes e até mesmo formativas para a condução pedagógica do processo educativo. Ao final, espera-se delinear a prática na formação docente, por meio de vivências de intervenção e observação nos locais de exercício da profissão, como parte fundante da tarefa de se formar professores.
\end{abstract}

PALAVRAS-CHAVE: Formação de professores. Método. Prática docente.

RESUMEN: Este ensayo trata de la epistemología de la formación de profesores a partir del trabajo educativo realizado por Célestin Freinet. La complejidad del ejercicio docente cotidiano es puesta en evidencia, siendo que, de las innumerables sendas epistemológicas posibles para el desarrollo de la profesión, el empirismo de Freinet es aludido como una de las formas más interesantes, instigadoras e incluso formativa para la conducción pedagógica del proceso educativo. Al final, se espera delinear la práctica en la formación docente, por medio de vivencias de intervención y observación en los lugares de ejercicio de la profesión, como parte fundadora de la tarea de formarse profesores.

PALABRAS CLAVE: Formación de profesores. Método. Práctica docente.

ABSTRACT: This essay deals with the epistemology of teacher education based on the educational work carried out by Célestin Freinet. Freinet's empiricism is alluded to as one of the most interesting, instigating and even formative forms for the pedagogical conduction of the educational process, as evidenced by the complexity of the daily teaching. In the end, it is hoped to delineate the practice in teacher education, through experiences of intervention and observation in the places of the profession, as a founding part of the task of training teachers.

KEYWORDS: Teacher training. Method. Teaching practice.

\footnotetext{
${ }^{1}$ Instituto Federal de São Paulo (IFSP), Itapetininga - SP - Brasil. Coordenadoria de Formação Pedagógica. Docente do PPG em Educação UFSCar/Sorocaba. ORCID <https://orcid.org/0000-0002-1870-7528>. Email: ivanfrt@yahoo.com.br
} 
As próprias crianças já não são o que éramos com a idade delas. Não têm as mesmas preocupações, nem os mesmos interesses, nem o mesmo caráter: modernizam-se também com grande rapidez e seu comportamento é deste modo modificado. O passado mudou de rosto. Ao tentarmos falar hoje a estas crianças, ou a estes jovens tão resolutos, surpreende-nos verificar que não escutam as mesmas palavras com o ouvido dos jovens de há dez anos e que não manifestam interesse pela nossa experiência pessoal (FREINET, 1975, p. 10).

O maior desafio cotidiano que os futuros docentes terá de enfrentar é justamente o futuro. É uma profissão que se transforma muito rapidamente, pois têm de acompanhar as mudanças da sociedade. Os alunos de hoje não são iguais a de 20 anos atrás e não serão iguais aos daqui a 20 anos, em termos de conhecimento que trazem para as aulas e de comportamento (PESSOA DE CARVALHO, 2016, p. 129).

Duas epígrafes balizam o início deste ensaio sobre epistemologia da formação de professores. A primeira, escrita na França em meados dos anos 1960, e a segunda no Brasil, cerca de 50 anos mais tarde. Distintos contextos histórico, geográfico, político, econômico, social e cultural se encontram em uma constatação muito eloquente, contundente e até óbvia: a educação escolar precisa se transformar constantemente. Contudo, o que Freinet (1975) anotou a respeito da diferença fundamental entre as gerações que se encontram no cotidiano escolar foi também identificado por Pessoa de Carvalho (2016), evidenciando que aquilo que é óbvio não tem sido, necessariamente, colocado em prática nas instituições de ensino.

Ambos os trechos citados na epígrafe são atemporais, praticamente servindo para qualquer lugar e/ou momento em que se esteja refletindo sobre a educação escolar. Freinet (1975) percebeu, no exercício diário de lecionar para os anos iniciais da escola, que as crianças "de hoje" são diferentes das crianças "de ontem", ou seja, percebeu que era preciso ensinar para uma geração bastante diferente da sua própria. Isso quer dizer que as coisas se transformam, o que implica mudanças de valores e atitudes culturais. Não compreender tais mudanças é potencializar conflitos entre quem ensina e quem aprende, portanto, é não educar. Pessoa de Carvalho (2016), na atividade de formar professores na Universidade de São Paulo, apresentou o futuro como maior desafio da carreira docente. Tal qual Freinet, a autora percebeu que os estudantes "de hoje" são diferentes dos estudantes "de ontem", assim como os "de amanhã" serão igualmente diferentes.

Destaca-se, assim, um primeiro problema para formação de professores: compreender que uma sala de aula não deve ser um espaço vicioso e alegórico, ignorando o mundo "lá fora", em constante transformação. Já na primeira metade do século passado, 
Freinet havia reconhecido esse tipo de trabalho educativo como sendo bastante infértil, estéril até, tomando atitudes para reverter essa distância entre a escola e o mundo que a cerca, onde a vida efetivamente acontece (FORTUNATO, 2016a). Claro que isso não é algo exclusivo do professor francês, tendo sido esquadrinhado e criticado por diversos pesquisadores, inclusive de forma bastante contundente (FORTUNATO, 2016b).

Saídas para esse problema identificado já foram delineadas em diversos lugares e de várias formas como, dentre outros, na centenária escola de Summerhill (FORTUNATO, 2018a), nas propostas revolucionárias de Paul Goodman (FORTUNATO; CUNHA, 2017) ou nas técnicas de ensino de Freinet (FORTUNATO, 2016c). Não obstante, parece que tais alternativas ainda são marginais, não tendo sido efetivamente incorporadas na massiva forma de se praticar a educação escolar. Afinal, tivessem sido congregadas no cotidiano das instituições de ensino, não encontraríamos Freinet (1975) e Pessoa de Carvalho (2016), em tempos e lugares tão distintos, apresentando exatamente as mesmas dificuldades, denunciando a inércia da escola.

Dessa constatação emerge um segundo problema para a formação de professores: a própria formação docente tende a ser redundante, ou seja, nela se reproduz a forma arcaica de ensinar, não permitindo que outras perspectivas sejam divisadas. Pessoa de Carvalho (2016) anotou essa contradição, ao indagar o seguinte: "se o formador tiver concepções de ensino tradicionais como irá formar um professor inovador?” (p. 131). Curiosamente, o mesmo questionamento já tinha sido minutado por Freinet (1975, p. 35), quando anotou o seguinte: "se os professores primários conservam ainda os velhos instrumentos, isto devese, por um lado, ao facto de não lhes ter ainda oferecido técnicas e utensílios de substituição mais práticos e mais factíveis".

Existe um propósito ao elencar esses dois problemas recorrentes e persistentes para formação docente, ou seja, a relação escola-mundo e a prática inercial, e ao assinalar que soluções para tais já foram identificadas e partilhadas há algum tempo: argumentar em favor da pedagogia Freinet como elemento fundante para a (constante) reconstrução de uma epistemologia da formação de professores. Para isso, é preciso ressaltar os elementos que balizaram sua atuação como professor, elencando aqueles que o distinguem das demais formas de ser professor.

Claro que a pedagogia Freinet não é algo desconhecido dos educadores. Apenas como exemplo, em 2017 foi publicado um dossiê sobre a atualidade de sua pedagogia 
nesta mesma revista ${ }^{2}$, na qual boa parte dos seus pressupostos foi analisada e avalizada por educadores nacionais e estrangeiros. Particularmente, inclusive, já recuperei sua pedagogia em outros ensaios, indicando-a como uma forma de tornar a educação formal menos inercial e mais progressista (FORTUNATO, 2016a; 2016b). Em outro trabalho, foi partilhada sua descoberta de que há invariantes pedagógicos para a prática educativa, tais como o fato de que os estudantes, adultos ou crianças, gostam de escolher o que estudar, que preferem fazer ao invés de apenas observar e que têm satisfação de produzir o que acham relevante para sua própria vida; ou de que a escola tradicional deve abolir seus métodos e salas de aula com mais de 25 alunos (FORTUNATO; CUNHA; TEMPLE, 2016).

Mesmo que a pedagogia Freinet não seja algo desconhecido dos educadores, parece que o seu estudo e sua prática para formação de professores ainda é algo bastante incipiente, ao menos no Brasil. Ao usar o mecanismo de busca do Portal de Periódicos $\mathrm{CAPES}^{3}$, o único artigo localizado com o uso do operador booleando AND para combinar os descritores "Freinet" e "formação de professores" foi um relato de experiência realizado, em 2002, por Sampaio e Vretnar (2017), tendo sido recuperado de uma brochura antiga e incluído no já referido dossiê sobre a pedagogia Freinet. A experiência retratada nesse artigo foi sobre a condução de um ateliê de alfabetização para doze educadores de nacionalidades diferentes, e como o trabalho, pela concepção freinetiana de ação e construção do próprio conhecimento, permitiu que os professores encontrassem outras linguagens para conseguirem se comunicar. Relato de experiência importantíssimo, todavia não ajuda a compreender como a pedagogia pode servir à formação docente.

Outro lugar de busca, contudo com saldo ainda menos fértil, foi o Google Acadêmico $^{4}$. Dos mais de 3000 resultados, nenhum trouxe algo específico da relação entre a pedagogia Freinet e a formação docente. Por fim, pude localizar trabalhos mais específicos dessa relação no catálogo de teses e dissertações da $\mathrm{CAPES}^{5}$, apesar de que apenas dois, dos 23 que retornaram da busca pela combinação dos descritores, tenham investigado como a pedagogia Freinet pode estar presenta na formação de professores. Curiosamente, foram duas teses, do mesmo programa de pós-graduação em educação da

\footnotetext{
${ }^{2}$ Dossiê disponível em: 〈https://periodicos.fclar.unesp.br/iberoamericana/issue/view/608/showToc〉. Acesso 24 fev. 2018

${ }^{3}$ Site do Porta: <http://www.periodicos.capes.gov.br/>. Acesso em: 24 fev. 2018.

${ }^{4}$ Site do Google Acadêmico: <https://scholar.google.com.br/>. Acesso em: 24 fev. 2018.

${ }^{5}$ Site do catálogo: < http://catalogodeteses.capes.gov.br>. Acesso em: 24 fev. 2018.
} 
Universidade Federal do Rio Grande do Norte, orientadas pelo mesmo docente, Francisco de Assis Pereira.

A tese mais antiga dentre as duas, de autoria de Cavalcanti (2006), leva o título de "Pedagogia Freinet: mediação para o social, o político, a formação de professores". Metade da tese é destinada à história e aos conceitos principais da obra de Freinet e como sua pedagogia chegou no Brasil. Na segunda metade, o autor descreve um longo processo de formação continuada em exercício realizada com cinco professoras de uma escola de educação fundamental. Por meio de leituras das obras de e sobre Freinet, observação das aulas das professoras, momentos de reflexão conjunta e visitas à escola Freinet de Natal/RN, Cavalcanti (2006, p. 163) narrou todas as etapas de desenvolvimento dessa formação continuada com as professoras, declarando que a prática da pedagogia Freinet ajudou-as a reconhecer a necessidade de dar "maior liberdade para expressão da criança", além de criar espaços pedagógicos para potencializar a criatividade, a autonomia e os saberes individuais de cada um de seus alunos.

A segunda tese localizada, desenvolvida por Sbrussi (2010), trata da formação inicial de professores, investigando como os fundamentos da pedagogia Freinet eram incorporados ao longo do curso de licenciatura em pedagogia da Universidade Potiguar, no Rio Grande do Norte, durante o período de seu doutorado (2007-2009). Sua proposta era bem clara, sendo enunciada da seguinte maneira:

A formação de professores, como pessoas em constante processo de convivência interativa, atravessa a obra freinetiana e a visão humanística de Célestin Freinet é essencial para influenciar uma prática docente comprometida com uma educação transformadora (SBRUSSI, 2010, p. 29).

A autora era professora no curso de pedagogia investigado e tinha participação ativa na disseminação das ideias e técnicas de Freinet para os futuros licenciados. Teoricamente, sua preocupação era cotejar o pensamento de Freinet com outros pensadores da educação, como que para demonstrar a validade de sua pedagogia. Por exemplo, Sbrussi (2010, p. 91) encontrou aproximações com a didática magna de Comenius, "pois ambos consideram a escola o lugar onde se devem colocar as coisas em ação, utilizando o cenário do mundo, libertando-se o professor de métodos coercitivos”. A autora também esboçou correlações com Paulo Freire e sua pedagogia libertária, com pensadores da formação de uma cidadania crítica, como Libâneo e Saviani, bem como com autores mais atuais da formação de professores, tais como Pimenta, Nóvoa e Cunha. 
Por atuar diretamente na formação de professores, no curso de licenciatura em pedagogia, Sbrussi (2010) conseguiu iniciar uma discussão a respeito da participação de Freinet na formação docente. Para a autora, a seguinte frase contém os elementos centrais do pensamento de Freinet a respeito de se tornar docente, sendo que um professor "deve preocupar-se que os alunos sejam bem sucedidos, ajudando-os se for preciso através da generosa participação, da nossa qualidade de professores; se os alunos se sentirem orgulhosos das suas obras serão capazes de ir muito longe" (FREINET, 1975, p. 58). Obviamente que ser bem sucedido implica reconhecer as próprias potencialidades e interesses, participando do mundo de forma ativa, crítica, cooperativa, autônoma e até mesmo cidadã.

Mas, para fazer isso, é preciso combater a antiga (porém atual) forma de se educar pela domesticação, pela inércia, pela contemplação..., promovendo uma educação escolar na qual os estudantes trabalham naquilo que lhes interessa. Esse combate requer preparar os docentes para essa maneira de educar, para a qual Sbrussi (2010) conseguiu localizar princípios que demonstravam essa intenção em Freinet. Segundo a autora:

Retomando as ideias de Freinet sobre formação de professores vimos que ele desde a década de 1950, bem antes da instalação dos cursos de formação contínua na França, já reunia quinzenalmente grupos que trabalhavam a sua pedagogia para socializar trabalhos, trocar ideias, dirimir dúvidas e relatar experiências exitosas. Igualmente, parte de sua correspondência era dedicada a responder aos professores questões sobre a sua prática pedagógica. [...] Ele sempre possibilitava que colegas mais experientes no exercício da docência freinetiana orientassem outros colegas compartilhando suas aprendizagens durante encontros e intercâmbios (SBRUSSI, 2010, p. 92).

Certamente, as atividades de formação de professores realizadas por Freinet à frente das cooperativas de ensino e do Movimento da Escola Moderna, por ele fundados, não correspondem aos trabalhos de formação docente existentes atualmente, realizados exclusivamente pela universidade. No percurso formativo universitário, é bastante comum o reforço da escola como lugar alegórico, pois estudar na universidade é também enfrentar desafios redundantes, que servem apenas para a própria universidade. Outro ensaio trata com propriedade da formação universitária para a docência como um círculo vicioso, pouco se relacionando com o mundo para o qual se preparam seus professores egressos (FORTUNATO, 2018b). Já nesse ensaio, as ideias de Freinet para a formação de professores começavam a tomar corpo sem, no entanto, terem sido pensadas 
especificamente como elementos fundantes de uma epistemologia para a formação docente.

Até aquele momento, todo ideal e as técnicas de Freinet para uma educação mais viva tinha como foco transformar a escolarização em algo mais construtivo, significativo e interessante para o alunado. Era como se eu buscasse uma educação renovada sem, contudo, ter percebido que essa renovação também requer mudanças substanciais nos fundamentos da formação docente. Mudanças no sentido de que é preciso encontrar uma formação capaz de inscrever os futuros professores no mundo concreto que temos fora da universidade, motivando-os a também ir ao encalço de uma prática de ensino que supere a inércia escolar. Embora tenha descrito diversas atividades cunhadas e realizadas em distintas disciplinas de cursos de formação de professores sob minha responsabilidade ${ }^{6}$, as quais foram catalisadas pelas propostas arrojadas de Célestin Freinet, essas não tinham sido efetivamente incorporadas no baldrame epistemológico da profissão docente.

Como apontamos no texto de abertura deste dossiê, a epistemologia é "um conceito que implica conhecer o conhecimento" (FORTUNATO; MENA, 2018). Dessa forma, ao reexaminar os pressupostos que têm balizado diversas investidas na formação de professores, fica evidente que a pedagogia Freinet participou de todas elas (FORTUNATO, 2018b; 2018c; 2018d; 2016d). Essa participação foi fundamental para ampliar perspectivas teóricas, ajudando a perceber, por exemplo, que aprender é algo intrínseco (seja aprender a falar e andar, seja aprender a abstração dos conteúdos escolares). Não obstante, sua participação também foi fundamental para transformar minha prática de ensino, permitindo que novos instrumentos fossem incorporados às aulas catedráticas (dialogadas ou expositivas), mas, principalmente, participando de uma reconstrução da sala de aula. Nessa reconstrução, a sala de aula passou a ser compreendida como local de aprendizado coletivo, especialmente no envolvimento com diversos lugares da educação e seus desafios concretos.

Já me referi à Freinet como um herói da educação, pois foi com ele que percebi que é possível promover diferentes formas de escolarização, não sendo necessário se render à secular prática tradicional, nomeada por ele de escolástica, termo, aliás, que ele retoma da proposta de educação da Idade Média (FORTUNATO, 2016a). Freinet demonstrou como pode ser possível transformar a educação escolar, substituindo as preleções (seguidas de

\footnotetext{
6 Trata-se da minha particular experiência como docente de didática e prática docente dos cursos de licenciatura, especialização e programa especial de formação docente no Instituto Federal de São Paulo (IFSP), campus Itapetininga.
} 
memorização) por técnicas que permitem que os educandos trabalhem e se envolvam com o que estão aprendendo, principalmente pela experimentação. Suas técnicas, tais como a aula-passeio (sair da classe para explorar o mundo), a imprensa e a correspondência escolar (lastreadas pelas produções de texto e desenho livre para comunicar-se), o livro da vida e as fichas de autoavaliação (formas de perceber-se e inserir-se no mundo) etc., foram elaboradas de modo a permitir que os estudantes tivessem o que fazer além de estar na escola e se esforçar para memorizar conteúdos abstratos.

Além de ter reconhecido o heroísmo de Freinet, deixei expresso alhures que seu legado "diz respeito a salutar inspiração ao magistério, sobre a qual professores podem se apoiar para pensar e repensar a própria prática e as contingências da profissão" (FORTUNATO, 2016c, p. 176). Nesse ensaio em que tratei de seu legado, pude elencar cinco lições aprendidas com as obras do e sobre o educador: (1.) aprender é natural e se dá por tentativa-e-erro; (2.) as técnicas de Freinet fazem sentido na educação formal, em qualquer nível e modalidade de ensino; (3.) a educação deve priorizar o bom-senso; (4.) exercer a docência pode se dar na base da tentativa-e-erro; e (5.) para que tenhamos uma educação renovada, é preciso insistir e persistir. À época, essas lições foram partilhadas como elementos de busca para a transformação do cotidiano escolar. Agora, é momento de reorganizá-las como parte fundante da formação docente, tentando responder, principalmente, às duas principais inquietações que balizaram este escrito: como agenciar uma efetiva relação escola-mundo e como promover formas fecundas de ensinar.

Podemos começar pela constatação inicial deste ensaio, expressa tanto por Freinet (1975), na França, na década de 1960, quanto por Pessoa de Carvalho (2016). No Brasil, na segunda década do século XXI, os estudantes pertencem a um contexto cultural e axiológico distinto do contexto em que os docentes eram estudantes. Diante dessa constatação, os professores, em formação ou em exercício, se veem em uma encruzilhada na qual os caminhos são: (1) reconhecer que o tradicionalismo da educação contemplativa e repetitiva não se insere no mundo vivido pelos estudantes, buscando meios de renovar; ou (2) continuar acreditando que somente se aprende pela sempiterna prática da escola tradicional, pois esta, há séculos, tem produzido fecundos resultados.

Claro que trilhar por qualquer um desses caminhos não pode ser entendido como uma simples escolha, pois isso seria reduzir e vulgarizar toda complexidade tanto da docência quanto da experiência escolar vivida, que atuam diretamente na construção, reconstrução e cristalização de crenças educacionais. Soares e Bejarano (2008) tratam com propriedade como se dá a elaboração dessas crenças, revelando como o contexto 
sociocultural influencia nesse processo, que é individual. Os autores esclarecem, ainda, que as crenças oferecem segurança, pois dão um sentido metafórico de "chão firme" para o desenvolvimento das ações cotidianas; ou seja, crenças constituem as certezas da vida e a garantia de que se está agindo de maneira correta. Por outro lado, Soares e Bejarano (2008) revelam que as crenças já cristalizadas não têm, necessariamente, relação direta com o cotidiano vivido, o que implica que as ações são tomadas independentemente das evidências concretas. Essa ideia a respeito das crenças educacionais e da forma como elas são elaboradas e se cristalizam ajudam a compreender porque, naquela encruzilhada apreendida com a pedagogia Freinet, a trilha seguida é quase sempre a da velha escolástica.

Assim, não se pode negar que essa trilha "funciona", isto é, egressos da escola conseguem ter autonomia e uma vida bem sucedida. Isso parece ser suficiente para dizer que não apenas seria desnecessário mudá-la, mas que não se deve, mantendo a educação escolar como ela sempre foi (talvez porque esta preencha as necessidades de uma sociedade competitiva e individualista). Essa tradicional escolástica foi qualificada por Freinet (1977a) como "desvitalizada", organizada de maneira mecânica, por meio de punição e recompensa "que arranca à criança o gosto de caminhar em frente, de se instruir e de criar" (p. 29). Eis então um adágio de Freinet (1977a, p. 70), que parece sintetizar os motivos pelos quais buscou a trilha da transformação das práticas educativas: “A Escola é a inimiga da tentativa".

Uma das críticas mais profundas de Freinet (2004) ao trabalho escolar é a relação que faz com a produção em massa da indústria. Contudo, o educador percebeu que a fábrica aprendeu o trabalho padronizado, seriado e mecânico com a escola, e não o contrário. Antes da linha de produção e montagem, a escola já tinha a sala organizada em fileiras, com material didático único para todos e a receita: todo mundo ao mesmo tempo, fazendo a mesma coisa, tendo que aprender tudo igual, conforme o esperado pelos responsáveis pela organização escolar. Para Freinet (2004), o trabalho em série, a fórmula mais eficiente da escolástica, é o que desvitaliza a educação. O educador via as crianças postadas em fila, mirando o professor ou o livro (ou a parede, ou o teto, ou, ainda, os próprios pensamentos...), reféns de explicações puramente intelectuais, abstratas na maioria das vezes, tendo que memorizar e repetir tudo o que era ouvido ou lido, exatamente da forma como era dito ou escrito. Mas, ainda bem que ele conseguiu divisar nova trilha: 
O bom senso e a experiência demonstram, pelo contrário, que não é pela explicação intelectual, pelo recurso às regras e às leis, que se faz uma aquisição, mas sim pelo mesmo processo geral universal de tentativa experimental que tem, desde sempre, regido a aprendizagem da língua e da marcha (FREINET, 1977b, p. 21, grifo do autor).

Eis, então, sua proposta para uma diferente trilha na educação: a tentativa experimental. De forma mais simples: a tentativa-e-erro. Epistemologicamente, isso é nomeado de empirismo que, por sua vez, pode ser tomado como algo construído sem metodologia, sem rigor, sem controle, portanto, "não-científico". Inclusive, o empirismo é a base daquilo que foi qualificado por Chalmers (1993) como afirmações singulares e indutivismo ingênuo - ou seja, somente se conhece o que se pode ver, ouvir e sentir, generalizando o mundo a partir da própria experiência. Não obstante, Freinet (1975) parecia não se importar com sua falta de rigor e de cientificidade na sua prática educativa. Importava, antes, a alegria dos estudantes e a constatação de que estavam se envolvendo com genuíno interesse naquilo que faziam, estivessem trabalhando na correspondência ou no jornal escolar, durante as aulas-passeio, na constante construção de seus livros da vida etc.

Contemporâneo de nomes importantes na busca de uma educação renovada, Freinet esteve sempre à margem, pois nunca foi da universidade; provavelmente por conta de suas próprias crença, afinal, o empirismo não entra na universidade. De forma eloquente, respondeu à altura críticas diversas à sua forma de trabalho construída fundamentalmente pelo empirismo, ou melhor, pela tentativa-e-erro de produzir um ensino que fosse, efetivamente, significativo:

[...] a senhora Montessori e Decroly eram médicos; os psicólogos suíços eram, antes de mais, pensadores; Dewey era filósofo. Eles tinham sentido, muitas vezes de maneira genial, a urgência das opções novas que o mundo nos ia impor; espalharam ao vento a boa semente de uma educação em liberdade: mas não eram eles quem trabalhava a terra onde ia germinar a semente, nem quem estava incumbido de levar terra à planta e de regar as jovens plantas tenras, acompanhando-as com solicitude até darem fruto. Obrigatoriamente deixavam isso ao cuidado dos técnicos de base que, na falta de organização, de instrumentos e de técnicas, não conseguiam converter os seus sonhos em realidade (FREINET, 1975, p. 17). 
Nessa citação estão alguns elementos importantes para compreender porque o empirismo é, com efeito, o elemento principal da guinada educativa tomada por Freinet. Afinal, não fosse seu contato direto com o cotidiano escolar, com as salas de aula cheias de crianças, provavelmente teria cedido aos ideais que não germinam, pois esses são gestados de longe, na universidade, de maneira praticamente laboratorial. Críticas mais contundentes a esse distanciamento entre o local de produzir novos saberes e os locais onde os saberes deveriam florir foram feitas em outro ensaio (FORTUNATO, 2018b). Nesse referido ensaio, apresentei e analisei a respeito da primeira vez que resolvi trabalhar com os estudantes de licenciatura de forma não-catedrática: ou seja, saímos da nossa sala de aula e fomos em direção e outras, em lugares onde o professor efetivamente atua. Nosso propósito não era "ver a teoria na prática", senão "ver a prática" e com ela aprender.

Indagava, então, se toda defesa de Freinet para a transformação da escola se beneficiaria se fosse colocada em prática nos cursos de formação inicial de professores. Ao levantar a hipótese de que a educação pode se tornar diferente se forem ofertadas, aos futuros docentes, formas diferentes de ensinar, era preciso, portanto, experimentar. Isso realizado sem qualquer rigor científico, mas pela tentativa experimental de se fazer, colocando a prática em evidência, sobrepondo-a a qualquer estudo teórico que pressupõe resolver a docência, o ensino, a aprendizagem e a escola. Isso não quer dizer preterir o estudo teórico, mas inverter a ordem tradicional que coloca as teorias em primeiro plano e a prática para outro momento, quase sempre depois que a licenciatura já foi concluída. É como se as palavras de Freinet $(1975$, p. 22) ainda estivessem ecoando: "nenhuma das teorias lidas e entendidas podia ser transposta para minha escola”.

AGRADECIMENTOS: à Profa. Dra. Maria do Rosário Silveira Porto pela leitura crítica, atenta e pitacos imprescindíveis para a conclusão deste manuscrito.

\section{REFERÊNCIAS}

CAVAlCANTI, E. A. G. Pedagogia Freinet: mediação para o social, o político, a formação de professores. Tese (doutorado em Educação). Natal: Universidade Federal do Rio Grande do Norte, 2006.

CHALMERS, A. F. O que é ciência, afinal? Trad. Raul Filker. São Paulo: Editora Brasiliense, 1993. 
FORTUNATO, I. Summerhill, ou o legado de A. S. Neill para a educação libertadora de cabeças bem-feitas. Revista Hipótese, Itapetininga, v. 4, n. 1, p. 3-13, 2018 a.

FORTUNATO, I. Ensinando futuros professores a ensinar: reflexões de uma experiência didática. Horizontes, Atibaia, v. 36, n. 3, 2018b. [no prelo]

FORTUNATO, I. A didática na formação inicial de professores: relato de experiência. Revista Ibero-Americana de Estudos em Educação, Araraquara, v. 13, n. 1, p. 269-276, 2018c.

FORTUNATO, I. Um curso de formação continuada de professores como lócus de pesquisa-ação: relato de experiência. Estreiadiálogos, Braga, v. 3, n. 1, 2018d. [no prelo]

FORTUNATO, I. Aprendendo com Célestin Freinet: o passado ainda é presente. Tendencias Pedagógicas, v. 27, p. 251-258, 2016a.

FORTUNATO, I. Ainda é preciso ter cuidado, escola?! Interscienceplace, Campo dos Goytacazes, v. 11, n. 2, p. 86-95, 2016 b.

FORTUNATO, I. 50 anos sem Célestin Freinet, 500 anos de retrocesso das práticas escolares. Journal for Educators, Teachers and Trainers, Granada, v. 7, p. 174-181, $2016 c$.

FORTUNATO, I. Ensinando futuros professores sobre literatura infantil: relato de experiência. Educação Temática Digital, Campinas, v. 18, n. 3, p. 710-716, 2016d.

FORTUNATO, I.; CUNHA, C. R. A deseduccação obrigatória, por Paulo Goodman. Revista Sem Aspas, Araraquara, v. 6, n. 2, p. 175-182, 2017.

FORTUNATO, I.; CUNHA, C. R.; TEMPLE, C. Célestin Freinet's pedagogical invariants: a pathway to free and collaborative school education. Quaderni di didattica della scrittura, Roma, v. 26, n. 2, p. 44-51, 2016.

FORTUNATO, I.; MENA, J. Sobre a epistemologia da formação de professores. Revista Ibero-Americana de Estudos em Educação, Araraquara, v. 13, n. esp. 2, p. 1881-1895, 2018.

FREINET, C. Pedagogia do bom senso. Tradução J. Baptista. São Paulo: Martins Fontes, 2004.

FREINET, C. O método natural I: a aprendizagem da língua. Trad. Franco de Sousa e Maria Antonieta Guerreiro. Lisboa: Editorial Estampa, 1977a.

FREINET, C. O método natural II: a aprendizagem do desenho. Trad. Franco de Sousa e Teresa Balté. Lisboa, Portugal: Editorial Estampa, 1977b.

FREINET, C. As técnicas de Freinet da Escola Moderna. Trad. Silva Letra. $4^{\mathrm{a}} \mathrm{ed}$. Lisboa, Portugal: Editorial Estampa, 1975. 
PESSOA DE CARVALHO, A. M. Entrevista. Revista Internacional de Formação de Professores, Itapetininga, v. 3, n.4, p. 128-131, 2016.

SAMPAIO, R. M. W.; VRETNAR, N. Alfabetização e correspondência: alfabetização do ponto de vista de dois cantos do mundo: um curso de formação de professores trabalhando com alfabetização. Revista Ibero-Americana de Estudos em Educação, Araraquara, v. 12, n. esp. 1, p. 644-648, 2017.

SBRUSSI, M. de P. B. P. O bordado de uma prática: a pedagogia Freinet e a formação do professor comprometido. Tese (doutorado em Educação). Natal: Universidade Federal do Rio Grande do Norte, 2006.

SOARES, I. M. F.; BEJARANO, N. R. R. Crenças dos professores e formação docente. R. Faced, Salvador, n. 14, p. 55-71, 2008.

\section{Como referenciar este artigo}

FORTUNATO, Ivan. A epistemologia da formação docente: o que se pode aprender com o empirismo de Freinet. Revista Ibero-Americana de Estudos em Educação, Araraquara, v. esp, n. 2, p. 1995-2007, dez., 2018. E-ISSN: 1982-5587. DOI: 10.21723/riaee.unesp.v13.iesp3.dez.2018.11904.

Submetido em: 27/02/2018

Aprovado em: 20/06/2018 